3. Wuster W. Taxonomic changes and toxinology: systematic revisions of the Asiatic cobras (Naja naja species complex). Toxicon. 1996;34:399-406.

4. Chu ER, Weinstein SA, White J, Warrell DA. Venom ophthalmia caused by venoms of spitting elapid and other snakes: report of ten cases with review of epidemiology, clinical features, pathophysiology and management. Toxicon. 2010;56:259-272.

5. Prescott RA, Potter PC. Hypersensitivity to airborne spitting cobra snake venom. Ann Allergy Asthma Immunol. 2005; 94:600-603.

\section{In Response to Wilderness Search Strategy and Tactics, by Phillips et al}

\section{To the Editor:}

We are writing regarding a recently published Concepts article, titled "Wilderness Search Strategy and Tactics." Although we have great respect for the authors and their work, we would like to highlight where some of the content of the article deviates from the scientific literature, and US-accepted practices, regarding search theory and its application to land search. Even though the article includes the disclaimer, "The views expressed in this paper...do not necessarily reflect the views of the National Park Service," the current and former positions of some of the authors, and the fact that the example search used throughout the article is set in a National Park (Yosemite), strongly suggest that the methodology described reflects current National Park Service (NPS) policies and procedures for conducting searches.

Unfortunately, several details in the article deviate from the methodology described in the 2011 Land Search and Rescue Addendum to the National Search and Rescue Supplement to the International Aeronautical and Maritime Search and Rescue Manual (LSA), ${ }^{2}$ a document to which the US Department of the Interior (including the NPS) is a signatory party. Our intention is to bring to the attention of the WEM readership differences between the methodology described in the article and current accepted US land search methodology.

1. The article suggests that the general search area be divided into "manageable units" (segments) based on characteristics of the intended resources and how to search, not factors implying where the subject is more or less likely to be. ${ }^{1(\mathrm{p} 173)}$ These factors are considered only after segments have been established and "each segment is assigned a value representing "probability of area.""1(p173) That is, the article suggests that decisions on how and where to search are made before any evaluation of where the subject is more or less likely to be located. This approach does not reflect the current state of search methods in the United States, which are included in the LSA. ${ }^{2}$ Specifically, this approach does not include consideration of regions of probability, ${ }^{2(\mathrm{p} 5-10)}$ proportional methods for estimating probability of containment $(\mathrm{POC}) /$ probability of area (POA) $)^{2(\mathrm{p5}-39)}$, and much more. In short, the methodology suggested in the article should not conflict with the LSA, which represents the standard of care regarding search in the United States and has been accepted by all federal agencies including the National Park Service.

2. The "O'Connor method"1(p174) establishes initial POA values starting with letters or numbers and eventually converting them to percentages. This method does not maintain proportionality, which is required by search theory and the LSA ${ }^{2(\mathrm{p} 5-39)}$, and therefore is not an acceptable method of establishing initial POA values. ${ }^{5(\mathrm{pp} 81-84)}$

3. The article suggests that "The segments with the higher POA values then receive higher search priority." $1(\mathrm{p} 174)$ Koester $^{3(\mathrm{p} 316)}$ is cited, but nothing on the page of the reference cited - or within the entire referencedescribes managing a search in this way. The end of the article also appears to suggest that segments be searched in order of highest to lowest POA. ${ }^{1(\mathrm{p} 175)}$ Searching segments in this order has no basis in search theory, ${ }^{5(\mathrm{p} 46), 9}$ is in conflict with the methodology described in the LSA, ${ }^{2(\text { part5) }}$ will often give far less than optimal results in terms of probability of success (POS) per unit of time, ${ }^{2(\text { section5-7),9 }}$ and should be discarded. ${ }^{5(\mathrm{pp} 98-99)}$

4. The article suggests that the "rest of the world" (ROW) be assigned a POA value. ${ }^{1(\mathrm{p} 174)}$ That is in conflict with search theory and the LSA, ${ }^{2}$ and appears to resurrect an old method of using POA in an inappropriate way secondary to a lack of full understanding of POS and its use. ${ }^{5(\mathrm{pp} 81-84)}$

5. The article's use of "coverage"1(p174) is in direct conflict with the definition and use of the same term in both the LSA and the scientific search theory literature. Coverage (also know as "coverage factor") is defined in the LSA, and in many other sources, as "the ratio of 'area effectively swept' (ie, the product of effective sweep width and total track line length [TTLL]) to the physical area that was searched." 2(p5-13),5-9

6. The article describes probability of detection (POD) as "...a value representing the searchers' confidence in their search area coverage..." that is "subjectively determined." $1(\mathrm{p} 174)$ It then defines POD as "the chance of locating the subject in a given area during a given search effort (eg, 'I had a $10 \%$ chance of finding the subject')." ${ }^{" 1(p 174)}$ This 
definition is incorrect. As per the LSA and the scholarly literature on which it is based, POD is the conditional probability of detecting the search object if it is in the area (segment) searched at the time of the search. ${ }^{2(\mathrm{p} 5-11), 4(\mathrm{p} 15), 6,8}$ The POD is a function of coverage (C), which is in turn a function of the effective sweep width, effort (TTLL) expended in the area (segment), and the physical size (area) of the segment searched. ${ }^{2(\mathrm{p} 5-13), 4(\mathrm{pp} 8-16), 6,8}$ Therefore, it is an objective, not a subjective, estimate. In addition, formal detection experiments performed in 2003 and 2004 showed zero correlation between searcher estimates of POD and their actual detection performance. ${ }^{4(p p 127-129)}$ Therefore, POD values based on polling the searchers themselves are of no value at best, and extremely misleading at worst.

7. The paper describes an "inherent subjectivity in this process" and suggests that "search professionals have researched techniques that will derive more accurate and objective values representing coverage." ${ }^{1(\mathrm{p} 174)}$ It goes on to suggest that "critical separation" and subjective estimates of detection from searchers can be somehow combined to result in POD. ${ }^{1(\mathrm{p} 174)}$ That is incorrect. So-called "critical separation" does not provide an estimate of effective sweep width, which is required to compute POD. In addition, the subjective approach to directly estimating POD has been removed from most of the land search and rescue (SAR) literature for more than a decade because it is no longer an accepted best practice for computing POD in land search. This approach is also in conflict with the method of computing POD described in the LSA. ${ }^{2(\mathrm{pp} 5-15)}$

8. The article's description of global positioning satellite (GPS) tracking and its use $\mathrm{e}^{1(\mathrm{pp} 174-175)}$ suggests a lack of understanding of POD and effective sweep width, and is inconsistent with the methodology described in the LSA. ${ }^{2}$ What appears to be completely lacking, and perhaps misunderstood, is effective sweep width, a common oversight in land SAR in decades past. ${ }^{5}$ Fortunately, land SAR has evolved in the past 10 years to incorporate these concepts in its best practices, and these practices are described in the LSA. ${ }^{2}$

Donald C. Cooper, PhD, MBA Executive Director of Medical Education and Research Akron General Health System Akron, $\mathrm{OH}$
John R. Frost, BS, MS

Program Manager, Search and Rescue Optimal

Planning System, US Coast Guard Office of Search and

Rescue, Washington, DC

\section{References}

1. Phillips K, Longden MJ, Vandergraff B, et al. Wilderness search strategy and tactics. Wilderness Environ Med. 2014;25:166-176.

2. US National Search and Rescue Committee (NSARC). Land Search and Rescue Addendum to the National Search and Rescue Supplement to the International Aeronautical and Maritime Search and Rescue Manual, Version 1.0. Washington, DC: US National Search and Rescue Committee; 2011. Available at: http://www.uscg.mil/hq/cg5/cg534/ nsarc/land_sar_addendum/published_land\%20sar\%20adden dum\%20(1118111)\%20-\%20bookmark.pdf. Accessed September 7, 2014.

3. Koester RJ. Lost Person Behavior: A Search and Rescue Guide on Where to Look-for Land, Air, and Water. Charlottesville, VA: dBS Productions; 2008.

4. Koester RJ, Cooper DC, Frost JR, Robe RQ. Sweep Width Estimate for Ground Search and Rescue. Prepared for US Department of Homeland Security, US Coast Guard, Operations (G-OPR), Contract DTCG32-02-D-R00010, Task Order DTCG32-03-F000012. Washington, DC: Potomac Management Group, Inc; 2004. Available at: http:// www.uscg.mil/hq/cg5/cg534/nsarc/detexpreport_2004_final_s. pdf. Accessed September 7, 2014.

5. Cooper DC, Frost JR, Robe RQ. Compatibility of Land SAR Procedures With Search Theory. Prepared for US Department of Homeland Security, US Coast Guard, Operations (G-OPR), Contract DTCG39-00-D-R00009, Task Order DTCG32-02-F-000032. Washington, DC: Potomac Management Group, Inc; 2003. Available at : http://www.uscg. mil/hq/cg5/cg534/nsarc/LANDSEARCHMETHODSREVIEw. pdf. Accessed September 7, 2014.

6. Koopman BO. Search and Screening: General Principles With Historical Applications. New York, NY: Pergamon Press; 1980. Available at: http://www.mors.org/Publications/Books for soft-cover re-prints.

7. Stone LD. Theory of Optimal Search. 2nd ed. Military Applications Section, Operations Research Society of America. Arlington, VA: ORSA Books. Now available through Institute for Management Science and Operations Research, Catonsville, MD. Available at: https://www.informs.org/pubs/topics-in-or/ book-list/theory-of-optimal-search.

8. Frost JR. Principles of search theory, parts I and II: detection, effort, coverage, and POD. Response. 1999;17:1-15.

9. Frost JR. Principles of search theory, parts III and IV: probability density distributions and optimal effort allocation. Response. 1999;17:16-23. 